\title{
Annotations
}

\section{Prophylaxis and febrile convulsions}

\begin{abstract}
Any decision about treatment should be made after an assessment of the potential advantages and disadvantages of such treatment. There are two possible advantages of giving prophylactic drugs after febrile convulsions: to prevent further febrile convulsions, and to prevent neurological damage resulting from such further convulsions and manifesting as later epilepsy, mental retardation, or other neurological abnormality. The possible disadvantages result from drug toxicity, the risk of overdose, and the cost, financially and in terms of NHS resources, of treating large numbers of children.
\end{abstract}

\section{The advantages}

\section{Prevention of recurrences.}

\section{Risk in untreated patients}

The risk of recurrence during the 2 years after the first febrile convulsion is about 30 to $40 \%$ overall. ${ }^{1-2}$ The factor which most influences this recurrence rate is the age of the child, the rate being about 40 to $50 \%$ for those under age 18 months at the time of the first convulsion, and 20 to $30 \%$ for those over 18 months. ${ }^{2}$ Half of second convulsions take place within 6 months of the first, and three-quarters occur within a year.

\section{Effect of prophylaxis}

The regular administration of phenobarbitone in adequate dosage (about $5 \mathrm{mg} / \mathrm{kg}$ per day) reduces the likelihood of recurrence by between 40 and $70 \%{ }^{3-6}$ Phenobarbitone and sodium valproate appear to be equipotent in this respect. ${ }^{5-7}$ Lack of information about other drugs-such as phenytoin or carbamazepine-makes it impossible to draw firm conclusions about their effectiveness.

\section{Prevention of neurological sequelae.}

\section{The risk}

Prolonged convulsions may be followed by mesial temporal sclerosis $^{8}$ and other neurological damage. $^{9-10}$ It seems however, that this risk might have been exaggerated. The most satisfactory epidemiological data came from the American National Institutes of Health. ${ }^{2}$ In their study, which included 1706 children with febrile convulsions, there were no deaths or permanent motor deficits and there was no evidence that febrile convulsions per se led to intellectual impairment. The risk of epilepsy up to age 7 years was $1.6 \%$ for children with febrile convulsions and $0.5 \%$ for controls. It was not significantly greater $(4 \%)$ after prolonged (>30 min) first convulsions than after uncomplicated first fits $(1 \cdot 5 \%)$. The progression, first simple convulsion $\rightarrow$ subsequent complicated convulsion $\rightarrow$ later epilepsy, did not occur. Of children whose first convulsion was simple, $1.4 \%$ went on to have a subsequent convulsion lasting at least 30 minutes. Assuming that a prolonged convulsion carries the same risk of later epilepsy as a prolonged first convulsion ( $4 \%$ ), the risk to a child who has had a first uncomplicated convulsion of having a subsequent prolonged convulsion followed by epilepsy is $1.4 \times 4 \%$-that is 0.56 per thousand, or 1 in 1780 . (If 'complicated' -that is $>15$ minutes, multiple, or focal, seizures are considered instead of prolonged seizures, the figure becomes $8 \times 1.4 \%$-that is 1.1 per thousand, or 1 in 890). These figures represent the maximum estimate of the risk of preventable epilepsy after a first convulsion which can be derived from the National Institutes of Health data although followup for longer than the 7 years of the study may show a greater (although probably not very much greater) risk. Most ( 75 to $80 \%$ ) complicated convulsions are first convulsions and are therefore not preventable by drug prophylaxis.

\section{Effect of prophylaxis}

Since the risk is small the possible effect of prophylaxis must be small too. The conclusion of the recent statement from the National Institutes of Health ${ }^{11}$ should be stressed: 'There is no evidence to support the concept that prolonged therapy with anticonvulsants prevents the development of epilepsy or significant neurological deficits.'

\section{The disadvantages}

\section{Drug toxicity.}

\section{Phenobarbitone}

Phenobarbitone produces behaviour disorder, generally irritability and hyperactivity, in 20 to $60 \%$ of 
children treated. ${ }^{12-13}$ In 10 to $20 \%$ of them the disturbance is severe. Phenobarbitone impairs memory and concentration in young children ${ }^{14}$ with obvious implications for learning if the drug is given for a long period. In young rats the administration of phenobarbitone inhibited brain growth. ${ }^{15}$

\section{Valproic acid}

The rare occurrence of life-threatening disorders in children taking valproic acid makes its use over long periods in large numbers of children questionable. Pancreatitis $^{16}$ and acute liver failure ${ }^{17}$ have been recorded. Although these complications are rare, many will consider that any such risk is not justifiable when treating a common and usually benign illness.

\section{Overdose.}

The introduction of any drug into a household with young children is inevitably accompanied by a risk of accidental poisoning. Few studies have referred to this risk but such poisoning occurred in $3 \%$ of patients in a Scandinavian ${ }^{4}$ and in $5 \%$ of patients in a British study (D P Addy, unpublished data).

\section{Financial cost.}

\section{Drugs}

As febrile convulsions are common the cost of treating all children who have had a convulsion would be large. In England and Wales the approximate yearly drug bill if all children had 2 years of prophylaxis after a febrile convulsion would be: using phenobarbitone $£ 36,000$; using sodium valproate $£ 1080000$ ( $\times 2$ for syrup); and using carbamazepine $£ 850000$ ( $\times 3$ for syrup). The National Institutes of Health consensus statement suggests that prophylaxis 'may be considered' in children with complex convulsions, those with a first-degree relative with epilepsy, and those who are neurologically abnormal. This would include $40 \%$ of all children with febrile convulsions. Treating all those under 12 months would include $20 \%$ and under 2 years $67 \%^{1}{ }^{1}$

\section{Laboratory and clinical services}

Evidence suggests that for prophylaxis to be successful each child must be seen regularly and drug compliance checked by measuring serum drug concentrations. ${ }^{5}$ Simply handing out the drug without such supervision is likely to lead to many of the disadvantages and none of the advantages of treatment. The cost of such careful follow-up in terms of laboratory services and medical and nursing time is likely to be far from negligible.

\section{Intermittent 'acute' prophylaxis}

General measures to avoid overheating, antibiotic treatment of bacterial infection, and antipyretic drugs - such as paracetamol (acetaminophen in the USA) - at times of fever all seem sensible although their efficacy in preventing convulsions is open to question.

Phenobarbitone given at times of fever is unlikely to be effective. ${ }^{5}$ It is possible to achieve therapeutic plasma concentrations within 1 or 2 hours of giving a large oral ${ }^{18}$ or intramuscular ${ }^{18-19}$ dose but passage of the drug into the central nervous system probably takes at least 4 hours $^{18}$ and a hypnotic effect is common with large doses.

Rectal diazepam given by parents or general practitioners at the onset of a convulsion may be effective in preventing status ${ }^{20-22}$ but its use has not been widespread (the drug is more rapidly absorbed after rectal than after intramuscular administration). In one study ${ }^{22}$ rectal diazepam given at times of fever was as effective as continuously administered phenobarbitone in preventing recurrences. Often however, parents are unaware that the child is feverish until a convulsion occurs and the prospect of a family being ruled by the thermometer and of children being subjected to rectal injection whenever the mercury passes a particular mark, is not one which can be viewed entirely with equanimity.

\section{Some well-known non-facts about febrile convulsions}

(1) Complex convulsions are more often followed by recurrences. This is not true. ${ }^{2} 23$

(2) Any recurrence is more likely to be severe. This is not true of second convulsions but may be true of third or subsequent ones. ${ }^{1}$

(3) Children who have recurrent convulsions are more likely to develop epilepsy. This only applies to neurologically abnormal children after at least three convulsions. ${ }^{24}$

\section{A personal view}

Epilepsy should not be treated until it occurs. The three risk factors defined by the American study, ${ }^{24}$ and given as reasons for prophylaxis in the consensus statement, ${ }^{11}$ are all unalterable when the decision about treatment is made and the risk which accompanies them is of later epilepsy and not of recurrent or severe febrile convulsions. The risk, even with more than one of these risk factors, is less than $10 \%$. To give prophylaxis for these reasons therefore, is to adopt the unjustifiable position of giving potentially harmful treatment in the hope of preventing an 
occurrence which has at least a $90 \%$ chance of not happening and which, if it did happen, would probably do so after the treatment had finished. Since no upper age limit can be given beyond which the risk no longer exists, treatment once started should logically be given for life.

In my view treatment can be justified in the following circumstances:

(1) If the physician considers that the diagnosis is epilepsy (in this respect Livingston's criteria ${ }^{25}$ are no longer generally accepted). The diagnosis of epilepsy is established if recurrent afebrile convulsions occur, and seems probable if there are recurrent convulsions with or without fever in a child who has a clear neurological abnormalitysuch as microcephaly, hydrocephalus, or cerebral palsy.

(2) For frequent convulsions (two in 6 months or three in 18 months seems to be a reasonable, although arbitrary, suggestion).

(3) If parental anxiety is exceptionally high especially in children under age 18 months.

No drug can be regarded as satisfactory but at present I prefer phenobarbitone to sodium valproate. Further trial of other drugs - such as carbamazepine -is, I think, warranted but I do not regard trials of drugs on unselected children after first febrile convulsions as any longer justifiable.

Rectal diazepam could be used more often for some families but I would favour using it to terminate convulsions rather than as prophylaxis at times of fever. In particular, parents whose child has had a prolonged convulsion might well be offered the comfort of having rectal diazepam available to cut short any future episodes.

\section{References}

1 Lennox-Buchthal M. Febrile convulsions. A reappraisal. Electroencephalog Clin Neurophysiol 1973; Supplement 32.

2 Nelson K B, Ellenberg J H. Prognosis in children with febrile seizures. Pediatrics 1978 ; 61: 720-7.

3 Faero O, Kastrup K W, Nielsen E L, Melchior J C, Thorn I. Successful prophylaxis of febrile convulsions with phenobarbital. Epilepsia 1972; 13: 279-85.

4 Wolf S M, Carr A, Davis D C, et al. The value of phenobarbital in the child who has had a single febrile seizure: a controlled prospective study. Pediatrics $1977 ; 59$ : 378-85.

5 Wallace S J, Aldridge Smith J. Successful prophylaxis against febrile convulsions with valproic acid or phenobarbitone. Br Med J 1980; 280: 353-4.

6 Ngwane E, Bower B. Continuous sodium valproate or phenobarbitone in the prevention of 'simple' febrile convulsions. Comparison by a double-blind trial. Arch Dis Child 1980; 55: 171-4.
7 Cavazzuti G B. Prevention of febrile convulsions with dipropylacetate (DepakineR). Epilepsia 1975; 16: 647-8.

8 Falconer M A, Serafetinides E A, Corsellis J A N. Etiology and pathogenesis of temporal lobe epilepsy. AMA Arch Neurol 1964; 10: 233-48.

9 Aicardi J, Chevrie J J. Convulsive status epilepticus in infants and children. A study of 239 cases. Epilepsia 1970; 11 : $187-97$.

10 Meldrum B. Physiological changes during prolonged seizures and epileptic brain damage. Neuropaediatrie 1978; 9: 203-12.

11 National Institutes of Health Consensus Development Panel. Febrile seizures: long-term management of children with fever-associated seizures. $B r$ Med $J$ 1980; 281 : 277-9.

12 Thorn I. A controlled study of prophylactic long-term treatment of febrile convulsions with phenobarbital. Acta Neurol Scand [Suppl] 1975; 51-52: Supplement 60: 67-73.

13 Wolf S M, Forsythe A. Behaviour disturbance, phenobarbital, and febrile seizures. Pediatrics 1978; 61: 728-31.

14 Camfield C S, Chaplin S, Doyle A-B, Shapiro S H, Cummings C, Camfield P R. Side effects of phenobarbital in toddlers: behavioural and cognitive aspects. $J$ Pediatr 1979; 95: 361-5.

15 Diaz J, Schain E J. Phenobarbital: effects of long-term administration on behavior and brain of artificially reared rats. Science $1978 ; 199$ : 90-1.

16 Camfield P R, Bagnell P, Camfield C S, Tibbles J A R. Letter: Pancreatitis due to valproic acid. Lancet 1979 ; $\mathrm{i}$ : 1198-9.

17 Suchy F J, Balistreri W F, Buchino J J, et al. Acute hepatic failure associated with the use of sodium valproate. Report of two fatal cases. $N$ Engl J Med 1979; 300: 962-6.

18 Jalling B. Plasma and cerebrospinal fluid concentrations of phenobarbital in infants given single doses. Dev Med Child Neurol 1974; 16: 781-93.

19 Brachet-Liermain A, Goutieres F, Aicardi J. Absorption of phenobarbital after intramuscular administration of single doses in infants. J Pediatr 1975; 87: 624-6.

20 Agurell S, Berlin A, Ferngren H, Hellström B. Plasma levels of diazepam after parenteral and rectal administration in children. Epilepsia 1975; 16: 277-83.

21 Knudsen F U. Rectal administration of diazepam in solution in the acute treatment of convulsions in infants and children. Arch Dis Child 1979; 54: 855-7.

22 Knudsen F U, Vestermark S. Prophylactic diazepam or phenobarbitone in febrile convulsions: a prospective controlled study. Arch Dis Child 1978; 53: 660-3.

23 van den Berg B J. Studies on convulsive disorders in young children. III. Recurrence of febrile convulsions. Epilepsia 1974; 15: 177-90.

24 Nelson K B, Ellenberg J H. Predictors of epilepsy in children who have experienced febrile seizures. $N$ Engl $J$ Med 1976; 295: 1029-33.

25 Livingston S. Comprehensive management of epilepsy in infancy, childhood, and adolescence. Springfield: Thomas, 1972.

D P ADDY

Dudley Road Hospital, Department of Paediatrics, Dudley Road, Birmingham B18 7QH 